\title{
Crown Structure of the Maxillary Molars in the Japanese Shrew Mole, Urotrichus talpoides (Insectivora, Talpidae)
}

\author{
By \\ Shintaro KONDO, Hajime HANAMURA*, Masahito NATORI** and \\ Eizo WAKATSUKI
The First Department of Oral Anatomy, Showa University School of Dentistry, 1-5-8 Hatanodai, Shinagawa-ku, Tokyo 142-8555, Japan Nagoya 464-8650, Japan
**Faculty of Science, Okayama University of Science, 1-1 Ridai-Cho, Okayama 700-0005, Japan \\ *The Second Department of Anatomy, School of Dentistry, Aichi-Gakuin University, 1-100 Kusumoto-cho, Chikusa-ku,
}

- Received for Publication, December 19, 1997 -

Key Words: Insectivora, Dilambdodont, Stylar shelf, Odontometry, Molarization

\begin{abstract}
Summary: The maxillary first and second molars $\left(M^{1}\right.$ and $\left.M^{2}\right)$ in the Japanese shrew mole, Urotrichus talpoides, were investigated using an odontometrical approach. The mesiodistal crown diameter was larger in $M^{1}$ than in $M^{2}$, while the buccolingual diameter of $M^{1}$ was nearly equal to that of $M^{2} . M^{2}$ was more compressed mesiodistally than $M^{1} . M^{1}$ had a large distal triangle on the stylar shelf. The mesial triangle of $M^{2}$ was slightly larger than the distal triangle. Despite being smaller than $M^{1}, M^{2}$ was less variable than $M^{1}$ in terms of size. The distal triangle of $M^{1}$ and the mesial triangle of $\mathrm{M}^{2}$ were well developed, and thus this area, which corresponds to the inflection point of the maxillary dental arch, was most likely the center of an occlusal function.
\end{abstract}

The Japanese shrew mole (Urotrichus talpoides) is an insectivora that is native to Japan. The maxillary molars display a dilambdodont pattern when viewed from an occlusal surface. In other words, the paracone, metacone, and the three stylar cusps (buccal styles) are connected by a W-shaped crista (ectoloph), which forms the buccal stylar shelf. This shelf is divided into two parts: the mesial and distal triangles. The shape of these triangles is speciesspecific, and depends on the molar type (Sakai and Hanamura, 1969, 1973). Therefore, the structure of the dilambdodont molar can be used to express the quantitative changes in these triangles. The present study investigated the differences in the maxillary first and second molars $\left(\mathrm{M}^{1}\right.$ and $\left.\mathrm{M}^{2}\right)$ in Urotrichus talpoides using an odontometrical approach. Special attention was paid to the structure of the triangles on the buccal stylar shelf.

\section{Materials and Methods}

Seventy skulls of Urotrichus talpoides housed at the Second Department of Anatomy, School of Dentistry, Aichi-Gakuin University were measured using a measure scope (Nikon, Japan), calibrated to $0.001 \mathrm{~mm}$. These materials were selected under the condition that wear was not visible under a stereo microscope. The crown dimensions measured (Fig. 1) were the buccal and lingual mesiodistal diameters (BMD and LMD), the mesial and distal buccolingual diameters (MBL and DBL), the dimensions of the triangles on the stylar shelf (mesiobuccal mesiodistal diameter, MBMD; mesiobuccal buccolingual diameter, MBBL; distobuccal mesiodistal diameter, DBMD; distobuccal buccolingual diameter, DBBL), and the buccolingual diameter of the protocone (MLBL). The standard used for measurements obtained outside the crown (BMD, LMD, MBL and DBL) was that of Hanamura et al. (1990).

The crown area were calculated as follows:

Crown area $(\mathrm{CrA})=\frac{\mathrm{BMD}+\mathrm{LMD}}{2} \times \frac{\mathrm{MBL}+\mathrm{DBL}}{2}$

Area of the protocone $(\operatorname{PrA})=\mathrm{LMD} \times \mathrm{MLBL}$

Area of the triangles on the stylar shelf:

Mesial triangle area $($ MtriA $)=\frac{\text { MBMD } \times \text { MBBL }}{2}$ 

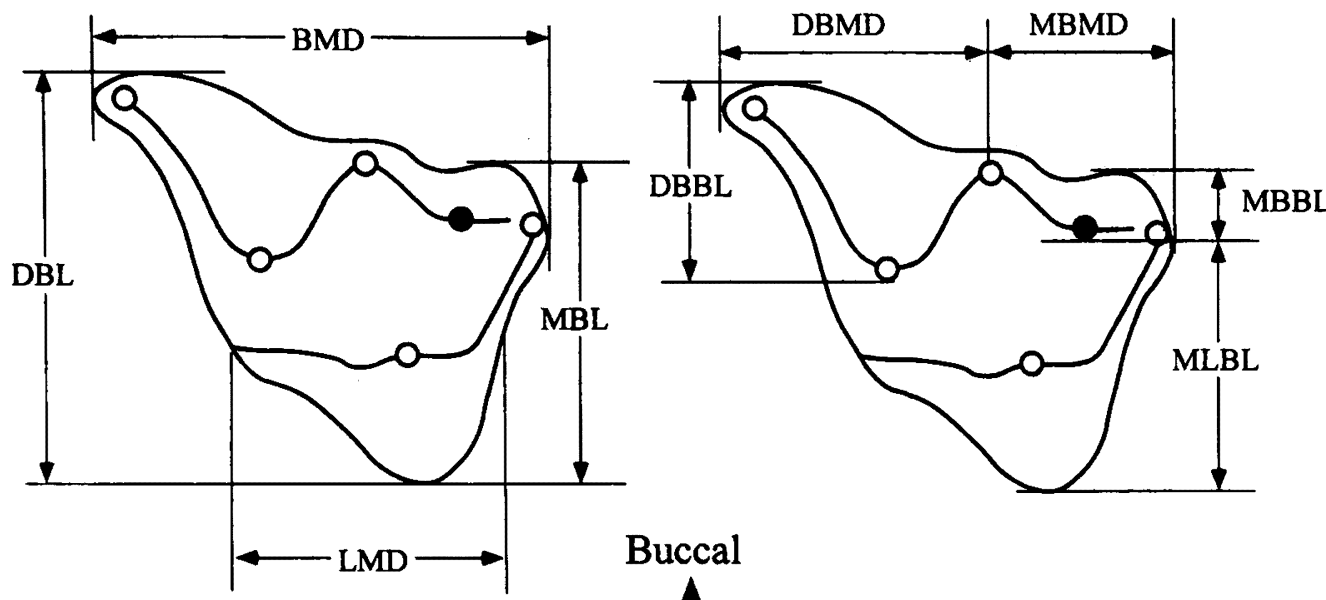

Buccal

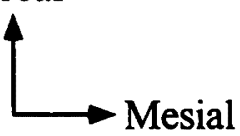

Fig. 1. Measurement of crown dimensions on the maxillary molars in Urotrichus talpoides.

Mesiodistal diameters

BMD: buccal mesiodistal diameter

LMD: lingual mesiodistal diameter

MBMD: mesiobuccal mesiodistal diameter

DBMD: distobuccal mesiodistal diameter

Buccolingual diameters

MBL: mesial buccolingual diameter

DBL: distal buccolingual diameter

MBBL: mesiobuccal buccolingual diameter

DBBL: distobuccal buccolingual diameter

MLBL: mesiolingual buccolingual diameter

Distal triangle area $($ DtriA $)=\frac{\mathrm{DBMD} \times \mathrm{DBBL}}{2}$

The crown indices were calculated as follows:

Crown index $(\mathrm{Cr}$ index $)=\frac{\mathrm{BL}}{\mathrm{MD}} \times 100$

For $\mathrm{MD}$ and $\mathrm{BL}$, the largest diameters for each direction are used: $M D$ is the $B M D$, and $B L$ is the larger of $\mathrm{MBL}$ and $\mathrm{DBL}$.

Mesiodistal diameter index (MD index)

$$
=\frac{\mathrm{LMD}}{\mathrm{BMD}} \times 100
$$

Buccolingual diameter index ( $\mathrm{BL}$ index)

$$
=\frac{\mathrm{DBL}}{\mathrm{MBL}} \times 100
$$

The crown area indices were calculated as follows:

Protocone are index $(\operatorname{Pr} A$ index $)=\frac{\operatorname{Pr} A}{\operatorname{Cr} A} \times 100$

Mesial triangle index $($ MtriA index $)=\frac{\text { MtriA }}{\operatorname{CrA}} \times 100$
Distal triangle index $($ DtriA index $)=\frac{\text { DtriA }}{\operatorname{CrA}} \times 100$

Individual relationships within the molar series were observed, and the size reduction of molar teeth was analyzed quantitatively according to the reduction index described by Fujita (1950). This index represents the size of the more reduced tooth $\left(M^{2}\right)$ relative to less reduced tooth $\left(M^{1}\right)$ as a percent. The molar size sequence (MSS) was determined for each crown dimension. When the reduction index of $M^{2}$ was less than $1 \%$, the MSS was $M^{1}=M^{2}$ for the purposes of calculation (Kondo et al., 1994).

Preliminary results revealed that molar size displayed no significant sexual dimorphism. In addition, for half the samples, the sexuality was obscure. For these reasons the data for both sexes were combined.

Descriptive statistical analysis, including distribution parameters was performed using JMP statistical software (SAS Institute Inc., Ver. 3.1.6) on a personal computer. Differences between measurements were analyzed using the student's t-test when the distribution was normal, and a nonparametric test (Wilcoxon's signed-rank test) for the remaining 
cases. Statistical significance was established at the $\mathbf{P}<0.05$ or $\mathbf{P}<0.01$ level.

\section{Results}

Figure 2 shows an SEM micrograph of the max- illary molars from an occlusal view. Tables 1,2 and 3 show the results of basic statistical analysis of crown dimensions and indices. Table 4 shows the reduction indices, and Table 5 shows the MSS in the crown dimensions.

Although $\mathrm{M}^{1}$ was larger than $\mathbf{M}^{2}$ for most of the crown dimensions, the MBBL, LMD and MBL were

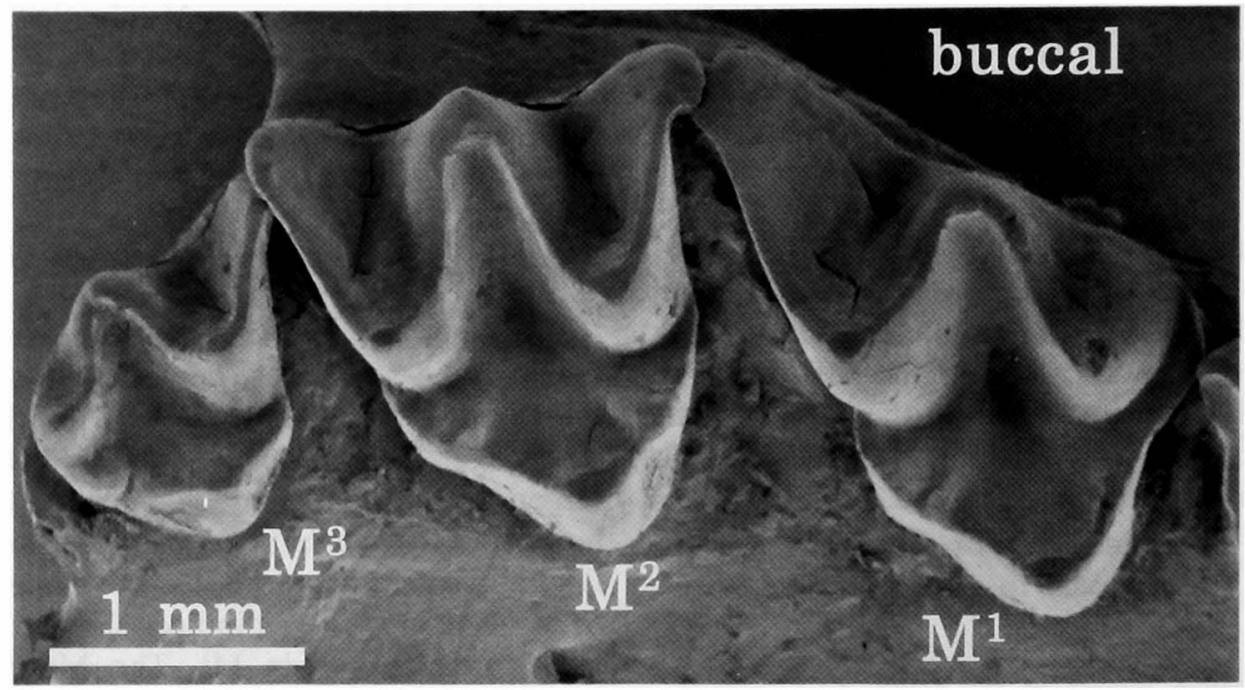

Fig. 2. SEM micrograph of maxillary molars from an occlusal view in Urotrichus talpoides.

Table 1. Basic statistics of crown dimensions, and results of a t-test between $\mathbf{M}^{1}$ and $\mathbf{M}^{2}(\mathrm{~mm})$

\begin{tabular}{|c|c|c|c|c|c|c|c|c|c|}
\hline & \multicolumn{4}{|c|}{$\mathbf{M}^{1}$} & \multicolumn{4}{|c|}{$\mathbf{M}^{2}$} & \multirow[b]{2}{*}{ t-test } \\
\hline & $\mathbf{N}$ & mean & SD & $\mathrm{CV}$ & $\mathbf{N}$ & mean & SD & $\mathrm{CV}$ & \\
\hline BMD & 67 & 2.099 & 0.109 & 5.195 & 68 & 1.829 & 0.079 & 4.334 & $\star$ \\
\hline LMD & 67 & 1.213 & 0.063 & 5.160 & 68 & 1.287 & 0.070 & 5.412 & $\star$ \\
\hline MBL & 67 & 1.827 & 0.086 & 4.717 & 68 & 1.898 & 0.085 & 4.454 & $\star$ \\
\hline DBL & 67 & 1.935 & 0.126 & 6.511 & 68 & 1.497 & 0.075 & 5.033 & $\star$ \\
\hline MBMD & 67 & 0.992 & 0.071 & 7.190 & 68 & 0.970 & 0.051 & 5.230 & $\Delta$ \\
\hline MBBL & 67 & 1.059 & 0.080 & 7.600 & 68 & 1.232 & 0.065 & 5.267 & $\star$ \\
\hline DBMD & 67 & 1.140 & 0.085 & 7.419 & 68 & 0.866 & 0.054 & 6.287 & $\star$ \\
\hline DBBL & 67 & 1.517 & 0.093 & 6.162 & 68 & 1.155 & 0.072 & 6.231 & $\star$ \\
\hline MLBL & 67 & 0.757 & 0.047 & 6.160 & 68 & 0.676 & 0.052 & 7.651 & $\star$ \\
\hline
\end{tabular}

$\star: P<0.01$, מ : $P<0.05$

Table 2. Basic statistics of crown areas, and results of a t-test between $\mathbf{M}^{1}$ and $\mathbf{M}^{2}\left(\mathrm{~mm}^{2}\right)$

\begin{tabular}{|c|c|c|c|c|c|c|c|c|c|}
\hline & \multicolumn{4}{|c|}{$\mathbf{M}^{1}$} & \multicolumn{4}{|c|}{$\mathbf{M}^{2}$} & \multirow[b]{2}{*}{ t-test } \\
\hline & $\mathbf{N}$ & mean & SD & $\mathrm{CV}$ & $\mathbf{N}$ & mean & SD & $\mathrm{CV}$ & \\
\hline $\mathrm{CrA}$ & 67 & 3.115 & 0.214 & 6.883 & 68 & 2.646 & 0.168 & 6.332 & $\star$ \\
\hline $\operatorname{Pr} A$ & 67 & 0.918 & 0.084 & 9.159 & 68 & 0.870 & 0.082 & 9.399 & $\downarrow$ \\
\hline MtriA & 67 & 0.525 & 0.057 & 10.843 & 68 & 0.598 & 0.052 & 8.624 & $\star$ \\
\hline DtriA & 67 & 0.864 & 0.075 & 8.729 & 68 & 0.500 & 0.049 & 9.790 & $\star$ \\
\hline
\end{tabular}

$\star: \mathrm{P}<0.01$ 
Table 3. Basic statistics of crown indices, and results of Wilcoxon-test between $\mathbf{M}^{1}$ and $\mathbf{M}^{2}(\%)$

\begin{tabular}{|c|c|c|c|c|c|c|c|}
\hline & \multicolumn{3}{|c|}{$\mathbf{M}^{1}$} & \multicolumn{3}{|c|}{$\mathbf{M}^{2}$} & \multirow[b]{2}{*}{ Wilcoxon-test } \\
\hline & $\mathbf{N}$ & mean & SD & $\mathbf{N}$ & mean & SD & \\
\hline $\mathrm{Cr}$ index & 67 & 92.49 & 8.18 & 68 & 103.90 & 5.86 & $\star$ \\
\hline MD index & 67 & 57.89 & 3.56 & 68 & 70.45 & 4.11 & $\star$ \\
\hline$B L$ index & 67 & 105.96 & 5.77 & 68 & 78.96 & 3.87 & $\star$ \\
\hline PrA index & 67 & 29.51 & 2.20 & 68 & 32.88 & 2.48 & $\star$ \\
\hline MtriA index & 67 & 16.86 & 1.28 & 68 & 22.62 & 1.62 & $\star$ \\
\hline DtriA index & 67 & 27.76 & 1.80 & 68 & 18.90 & 1.33 & $\star$ \\
\hline
\end{tabular}

$\star: \mathrm{P}<0.01$

significantly larger in $M^{2}$ than in $M^{1}(P<0.01)$ and the reduction index of MBBL was the largest of all dimensions $(116.72 \%)$. The smallest difference between $\mathbf{M}^{1}$ and $\mathbf{M}^{2}$ was noted in the MBMD. The reduction index was $98.27 \%$, and the MSS showed that $\mathbf{M}^{1}>\mathbf{M}^{2}$ in $48.48 \%$ of cases, while $\mathbf{M}^{1}<\mathbf{M}^{2}$ in $34.85 \%$. With respect to crown area, the MtriA was larger in $\mathbf{M}^{2}$ than in $\mathbf{M}^{1}$. The other areas were larger in $M^{1}$ than in $M^{2}$. In particular, the DtriA

Table 4. Reduction indices of the crown dimensions in $\mathrm{M}^{2}(\%)$

\begin{tabular}{lrrr}
\hline & N & mean & SD \\
\hline BMD & 66 & 87.40 & 5.59 \\
LMD & 66 & 106.28 & 8.03 \\
MBL & 66 & 103.74 & 4.85 \\
DBL & 66 & 77.26 & 4.56 \\
MBMD & 66 & 98.27 & 8.50 \\
MBBL & 66 & 116.72 & 10.27 \\
DBMD & 66 & 76.21 & 7.12 \\
DBBL & 66 & 76.09 & 5.54 \\
MLBL & 66 & 89.20 & 7.26 \\
CrA & 66 & 84.87 & 5.61 \\
MtriA & 66 & 114.77 & 14.66 \\
DtriA & 66 & 57.94 & 6.40 \\
PrA & 66 & 94.79 & 10.28 \\
\hline
\end{tabular}

was small in $\mathbf{M}^{2}$, and the reduction index was $57.94 \%$.

The crown proportion was compared using the crown indices. The crown index was significantly larger in $\mathrm{M}^{2}$ than in $\mathrm{M}^{1}(\mathrm{P}<0.01)$. The $\mathrm{BL}$ of $\mathrm{M}^{2}$ was larger than that of $M^{1}$. The $M D$ index was larger in $M^{2}$ than in $M^{1}$, while the $B L$ index was larger in $\mathbf{M}^{1}$ than in $\mathbf{M}^{2}$. Therefore, the mesial and lingual parts of $\mathbf{M}^{1}$ were less developed than those of $\mathrm{M}^{2}$. The crown area indices showed the $\operatorname{PrA}$ was larger in $\mathbf{M}^{2}$ than in $\mathbf{M}^{1}$. The MtriA index was also larger in $\mathbf{M}^{2}$ than in $\mathbf{M}^{1}$, while the DtriA index was larger in $\mathrm{M}^{1}$. These results again demonstrated that the mesial part of $\mathbf{M}^{1}$ was less developed than that of $\mathbf{M}^{2}$.

Comparison of the coefficients of variation (CV) showed that $\mathrm{M}^{1}$ varied more than $\mathrm{M}^{2}$ in size with the exception of the protocone size (LMD, MLBL). In particular, the variability of the region on the stylar shelf in $\mathbf{M}^{1}$ were large.

Figure 3 shows a schematic representation of the crown in the molars. The MD was larger in $\mathrm{M}^{1}$ than in $\mathrm{M}^{2}$, while the $\mathrm{BL}$ of $\mathrm{M}^{1}$ was nearly equal to that of $\mathrm{M}^{2} . \mathrm{M}^{2}$ was more compressed mesiodistally than $\mathbf{M}^{1}$. As for the triangles on the stylar shelf, $\mathbf{M}^{1}$ had a large distal triangle. $\mathbf{M}^{2}$ had a slightly larger mesial triangle than the distal triangle.

Table 5. Molar Size Sequences (MSS) in the crown dimensions

\begin{tabular}{|c|c|c|c|c|c|c|}
\hline & \multicolumn{2}{|c|}{$\mathbf{M}^{1}>\mathbf{M}^{2}$} & \multicolumn{2}{|c|}{$\mathbf{M}^{1}=\mathbf{M}^{2}$} & \multicolumn{2}{|c|}{$\mathbf{M}^{1}<\mathbf{M}^{2}$} \\
\hline & $\mathbf{N}$ & $\%$ & $\mathbf{N}$ & $\%$ & $\mathbf{N}$ & $\%$ \\
\hline BMD & 64 & 96.97 & 2 & 3.03 & 0 & 0.00 \\
\hline LMD & 10 & 15.15 & 5 & 7.58 & 51 & 77.27 \\
\hline MBL & 8 & 12.12 & 12 & 18.18 & 46 & 69.70 \\
\hline DBL & 66 & 100.00 & 0 & 0.00 & 0 & 0.00 \\
\hline MBMD & 32 & 48.48 & 11 & 16.67 & 23 & 34.85 \\
\hline MBBL & 1 & 1.52 & 2 & 3.03 & 63 & 95.45 \\
\hline DBMD & 66 & 100.00 & 0 & 0.00 & 0 & 0.00 \\
\hline DBBL & 66 & 100.00 & 0 & 0.00 & 0 & 0.00 \\
\hline MLBL & 59 & 89.39 & 3 & 4.55 & 4 & 6.06 \\
\hline
\end{tabular}





Fig. 3. Schematic representation of maxillary molars in Urotrichus talpoides.

\section{Discussion}

Although many descriptive studies of dilambdodont molars have been published, little is known about their quantitative structure. The dentition of Talpidae has been described in detail by Sakai and Hanamura (1973). $\mathbf{M}^{1}$ has a well developed distobuccal region, but a poorly developed mesiobuccal region. $\mathbf{M}^{2}$ differs from $\mathbf{M}^{1}$ in the poor development of the distobuccal region, and $M^{2}$ is more reduced mesiodistally. Sakai (1981) has reported the statistics of molar size and crown indices in Urotrichus talpoides. Although the method he used to measure molar dimensions differed from ours, and thus his results cannot be directly compared to ours, his finding that $\mathbf{M}^{1}$ was larger mesiodistally than $\mathbf{M}^{2}$, and smaller buccolingually, agreed with the results of the present study.

An odontometrical study of dilambdodont molars has been performed in other species, such as, Suncus murinus (Soricidae) (Hanamura et al., 1990) and Tupaia glis (Scandentia) (Kondo et al., 1994). In both species $\mathrm{M}^{1}$ has a larger MD than $\mathrm{M}^{2}$, while $\mathrm{M}^{2}$ has a larger BL than $M^{1}$. $M^{1}$ has a larger DBL than $\mathrm{MBL}$, and $\mathrm{M}^{2}$ has a larger MBL than DBL. These findings are also in agreement with those of the present study. It is likely that $\mathrm{M}^{2}$ is compressed mesiodistally, but prolonged buccolingually in comparison with $\mathbf{M}^{1}$. The mesiobuccal region of $\mathbf{M}^{1}$ is less developed than $\mathbf{M}^{2}$.

These structures in the dilambdodont molars seem to be closely related to the proportional differences between the mesial and distal triangles on the stylar shelf. In the present study the MtriA was larger in $\mathbf{M}^{2}$ than in $\mathbf{M}^{1}$, while the DtriA was larger in $\mathbf{M}^{1}$ than in $\mathbf{M}^{2} . \mathbf{M}^{2}$ had the slightly larger mesial triangle than distal one, but the difference between the two triangles was smaller in $M^{2}$ than in $M^{1}$. These proportional differences between $\mathbf{M}^{1}$ and $\mathbf{M}^{2}$ are in agreement with those found for Suncus murinus and Tupaia glis above.

Sakai (1981), analyzing regional differences in Urotrichus, concluded that the least size variability was found in $\mathbf{M}^{2}$, which agrees with the results of the present study. Similar findings in Tupaia have been reported by Kondo et al. (1994), and in Indriidae (Primates) by Gingerich and Ryan (1979). An association between early formation and low morphological variability in $\mathbf{M}^{1}$ was noted by Gingerich (1974). In the case of Urotrichus, Tupaia and Indriidae, $\mathbf{M}^{2}$ is less variable than $\mathbf{M}^{1}$ despite developing later, and thus the ontogenetic explanation is not always accurate. Another hypothesis has proposed that variability is related to occlusal complexity (Gingerich and Schoeninger, 1979).

Kondo et al. (1994) concluded that the occlusal function in the molar field concentrated at the inflection point of the maxillary dental arch in $T u$ paia. The maxillary arch curve is pear shaped in Tupaia. The arch width generally increases from $\mathbf{I}^{1}$ to $\mathbf{M}^{1}$, and decreases from $\mathbf{M}^{2}$ to $\mathbf{M}^{3}$. The inflection point of the arch curve corresponds to the area 
between the distal half of $\mathbf{M}^{1}$ and the mesial half of $\mathrm{M}^{2}$. In this area the molars are well-developed buccolingually. This configuration was also found in Urotrichus. Because the distal triangle of $\mathbf{M}^{1}$ and the mesial triangle of $\mathrm{M}^{2}$ are well developed, this area is most likely the center of an occlusal function. The variability of crown dimensions did not differ greatly within $\mathrm{M}^{2}$, while the dimensions of the stylar shelf were clearly variable in $\mathbf{M}^{1}$. Although large, the distal triangle of $\mathbf{M}^{1}$ was not stable. The protocone region was less variable in $\mathbf{M}^{1}$. The protocone is closely related to opposition, whereas the ectoloph is related to the shearing in an occlusion. Thus, the functional structure of $\mathbf{M}^{1}$ appears to differ from that of $M^{2}$. The crown shape of $M^{2}$ seems to indicate an occlusal function due to the stability of $\mathbf{M}^{2}$. Therefore, $\mathbf{M}^{2}$ has a stable crown structure despite its size small.

\section{References}

1) Fujita T. On the reduction index. Acta Anat Nippon 1950;
25:196. (Abstract, in Japanese)

2) Gingerich PD. Size variability of the teeth in living mammals and diagnosis of closely related sympatric fossil species. J Paleont 1974; 48:895-903.

3) Gingerich PD and Ryan AS. Dental and cranial variation in living Indriidae. Primates 1979; 20:141-159.

4) Gingerich $P D$ and Schoeninger MJ. Patterns of tooth size variability in dentition of primates. Am J Phys Anthrop 1979; 51:457-466.

5) Hanamura $H$, Ishikawa $A$ and Namikawa $T$. Molar size difference between two strains derived from the house musk shrew (Suncus murinus, Insectivora) in Bangladesh and Japan. J Growth 1990; 29:227-238. (in Japanese with English summary)

6) Kondo S, Hanamura $\mathrm{H}$ and Wakatsuki E. Crown dimensions of the maxillary molars in Tupaia glis. Okajimas Folia Anat Jpn 1994; 70:261-266.

7) Sakai E. A study on variation in dentition of Japanese shrew mole, Urotrichus talpoides (Talpidae, Insectivora). Jpn J Oral Biol 1981; 23:750-789. (in Japanese with English summary)

8) Sakai $T$ and Hanamura H. A morphological study on the dentition of Insectivora. I. Soricidae. Aichi-Gakuin J Dent Sci 1969; 7:1-26. (in Japanese with English summary)

9) Sakai T and Hanamura H. A morphological study on the dentition of Insectivora. II. Talpidae. Jpn J Oral Biol 1973; 15:333-346. (in Japanese with English summary). 